\title{
Gating and Syntactical Analysis of Spatial Configuration of Sectors of Gurgaon (Gurugram), India
}

\author{
Ajay Kaushik
}

\begin{abstract}
Published online: 25 January 2019
To cite this article: Ajay Kaushik (2018). Gating and syntactical analysis of spatial configuration of sectors of Gurgaon (Gurugram), India. Journal of Construction in Developing Countries, 23(2): 87-106. https://doi.org/10.21315/jcdc2018.23.2.6.
\end{abstract}

To link to this article: https://doi.org/10.21315/jcdc2018.23.2.6

\begin{abstract}
The formation of Haryana Urban Development Authority (HUDA) in 1977 paved the way for a planned growth of the state of Haryana. Development of neighbourhoods, in the form of sectors, has witnessed great transition since the inception of this regulatory body. Sectors of Gurgaon that were developed before HUDA came into existence showcase a different form of urban development. Gating is one of the contemporary phenomenons of urban development. Ever since the involvement of private developers in urban development, gating has become an unavoidable part of neighbourhood development. Gated developments lead to full control over the street network of the development. This paper tries to bring out the difference in the changing street pattern through syntactical analysis of streets of sectors. The main objective is to understand the configurational differences in the neighbourhood street pattern by using syntactical parameters of street network. For this objective, three different sectors (Sector 4, 56 and 49) showcasing different growth patterns have been compared and analysed. The study has been divided into five major parts with the first part introducing the problem. The second part of the paper through literature review discusses various space syntax parameters/characteristics and presents their definitions. The third part presents methodology of study and introduces the case study areas. The fourth part puts forth the result and the fifth one draws conclusion of the entire study. The study reveals Sector 4 as more intelligible and having higher synergy value compared to sector 49 which is completely gated and privately developed.
\end{abstract}

Keywords: Street pattern, Space syntax, Configuration, Intelligibility, Synergy

\section{INTRODUCTION}

Since the beginning of human civilisation, cities have been developing rapidly. According to United Nations Population Fund (UNFPA) 2007 report, by 2008, for the first time, more than half of the globe's population, 3.3 billion people, will be living in towns and cities (UNFPA, 2007). This situation poses a great challenge to the development agencies. Expanding population in the cities gives rise to the need of more accommodation and work space, which in turn leads to an increase in development activities. The contemporary cities stretch beyond their physical limits and the signs of growth are manifested in the form of vertical development towering over the low rise neighbouring buildings. The high rise residential, commercial and office towers in the vicinity of low rise developments are no longer surprising. 
Post liberalisation and especially in the past decade, half cities have seen faster transition, all over the world. India, is no exception. Its cities are growing at a fast pace and Gurgaon in the state of Haryana has witnessed such a growth. In 1991, the district Gurgaon had an urban population of around 121,000 and by 2011 , it had a population of 1.5 million (Census of India, 1991; 2011). It is in close proximity to the affluent southern part of Delhi. It is also located near to international airport of Delhi while the geographical location gives it an advantage over other cities of Haryana.

Since the last decade and half, the high rise developments are a vogue in the city. According to Pooja Mehtani, it has been referred to as an icon of India's growth and development at various platforms internationally (Mehtani, 2012). As of 2013, there are many companies that have setup their businesses in Gurgaon. Some of them are American Express, General Electric, Motorola, Dell, Microsoft, International Business Machines (IBM) and Google (Rajagopalan and Tabarrok, 2014). The liberal economic policies after the post reform period have also given a major push to the overall development of Gurgaon's economy. Many cities across the world draw parallel in the development and growth pattern and scale. Large cities are becoming global in scale and size of development.

According to the Regional Plan 2021 for National Capital Region (NCR), the area constituting Haryana Sub-Region is $13,428 \mathrm{sq} \mathrm{km}$. Out of this the Gurgaon region is $1,254 \mathrm{sq} \mathrm{km}$ with a population of over 1.5 million (Department of Town and Country Planning, Haryana, 2010; Census of India, 2011). Gurgaon is the main focus of this paper, as Gurgaon is the most dynamic city representing astounding growth in Haryana. Twenty years back, in early 1990s, Gurgaon used to be a small town lacking proper infrastructure, but now it has achieved an unprecedented growth rate and set up new trends with the contribution of private developers. Geographically it is in the vicinity of southern part of Delhi. It has gained due to its close proximity to Delhi International Airport. Its strategic location has triggered its growth. National Highway $8(\mathrm{NH}-8)$ passes through the city and divides the city in two distinctly identifiable parts. The north of the $\mathrm{NH}-8$ is called old Gurgaon and the southern part is called New Gurgaon (Mehtani, 2012).

The overall atmosphere in the city was conducive for the private developers to make investments. All this took place immediately after the formation of Haryana Urban Development Authority (HUDA) (Mehtani, 2012).

\section{Problem Statement}

In recent times, the new sectors in Gurgaon city are being developed completely with the help of private developers. Government's role is limited to the preparation of Master Plan. These developers buy land from the land owners at market prices. According to the development plan of the sector, the developers have to surrender that part of their land that falls in the public sector roads. The rest of the land that the developers own is distinctly marked and protected by putting up boundaries and gates. Thus gating and boundary come into picture. No one is allowed to cross or pass through the gated complex without permission. This increases the distance travelled by users, and such developments present a discontinuous, segregated and fragmented image of the sector. Sector 49 of the city is one such sector developed with the initiative of private developers. Sector 4 , on the other hand, is developed completely as a result of government planning exercise. Sector 56 
has mixed kind of development. It has gated cooperative group housing as well as HUDA developed low rise development as well. The paper investigates the segregated street pattern generated in the three sectors through syntactical analysis. There are some other reasons valid for the morphological development of an area viz: Master Plan regulations, floor area ratio (FAR), demand and market forces and historical reasons, etc.

However, gating in question is manifestation/implication in privately developed sector.

\section{LITERATURE REVIEW: THEORY OF SPACE SYNTAX}

During 1980s the initial studies and theory of space syntax were developed in Bartlett School of Architecture at University College of London (Paul, 2011). The scholars focused on the understanding of structure of space. The seminal book by Professor Bill Hillier and his colleague Julliene Hanson in the year 1984 called "Social Logic of Space" brought revolutionary change in the way space could be understood and defined with the theoretical ideas of space syntax (Hillier and Hanson, 1984). Now efforts were made to quantify space with its social relevance. The book deliberates upon the impact of spatial configuration of social life and other wise.

According to Abhijit Paul, space syntax is a theory with the help of which we understand spaces at building and urban level. Configuration of spaces, i.e interrelationship of spaces is the basic primary aspect of understanding a space (Paul, 2011). Thus, "configuration" by definition is a way to relate and understand spaces with respect to one another. The relationship of spaces is not only crucial pair wise but also within the whole pattern. It is also defined as pattern of connection/ links/etc. with other spaces (Kaushik, 2016: 24).

The theory of space syntax helps us to identify the constituent elements, their mutual relationship and an overall spatial configuration (Hillier and Hanson, 1984; Hillier, 2007).

Space Syntax, thus is a method with the help of which one can measure the topological relationship of one space with other spaces (Long, 2007).

\section{Syntactical Parameters}

With the help of axial map in space syntax the spatial configuration of any urban environment can be made. The important syntactical measures of spatial configuration of an axial map are depth connectivity, global and local integration, intelligibility and synergy (Long, 2007).

\section{Depth}

It can be defined as the smallest number of syntactic steps topologically that are needed to reach one space from another or from one axis to the other. Depth is counted in a graph and is determined by parameter, k. Parameter connectivity considers immediate neighbors (with parameter, $k=0$ ) and depth considers the neighbors of the $k$-th degree (Dettlaff, 2014). 


\section{Connectivity}

Connectivity is the most fundamental concept in space syntax theory. It may be applied to nodes and axes as well. For nodes, it is the degree of a node and can be defined as the number of other nodes directly connected to it and for axis it is the number of axes that are directly connected to it. According to Mahmoud (2010), it is the most apparent parameter for morphological analysis and measures the number of nearby neighbouring axes directly connected to a space. It identifies and specifies the number of immediate neighbors of an axis.

It is also defined as the way how well an axis is intersected by other axial lines (Long, 2007). Longer is a line more chances it has to have higher connectivity thus length of an axial line has a correlation to connectivity (Jiang as cited in Long, 2007)

\section{Integration}

Priya Choudhary mentions that "integration of a space is by definition expressed by a value that indicates the degree to which that space is integrated or segregated from a system as a whole (global integration), or from a partial system consisting of spaces a few steps away (local integration)" (Choudhary and Adane [2012] as cited in Kaushik [2016: 27]).

Space syntax also quantifies the way in which one line is connected to the other or all other lines in the system. A system of lines is shallow or deep when few or many intervening lines have to be traversed when going from one line to the other. A space is said to be integrated when all other spaces are relatively shallow from it (Long, 2007).

It is a value that defines the degree to which an axial line is more integrated or segregated in the system. An axial line with higher integration value has low mean depth value and vice versa. In simple terms, a high integration value line is more accessible in the system.

According to Paul (2011: 4), "Integration is the fewer intervening lines which need to be passed through to go from a line to every other line. It's in contrast with mean depth (obtained by dividing the total depth by $k$, the number of spaces in the system), the most integrated lines means minimum depth. In other words, integration is $1 /$ mean depth so the more segregated spaces mean higher depth". Thus, it is also known as availability.

\section{Local integration}

Several authors have argued that local integration is generally related to the pedestrian scale of movement. While calculating local integration one takes care that the elements of the degree of distant depth equal to 3. Scholars also say that distance wise it is about 1,250 $\mathrm{m}$ which is taken as a ray from the starting point. Measurements at a distance of up to five syntactic steps constitute the local integration (Dettlaff [2014] as cited in Kaushik [2016])

\section{Global integration}

According to Hillier and Hanson, global integration considers the distance from the starting point to all points in the system (Hillier and Hanson, 1984) 


\section{Intelligibility}

According to Choudhary and Adane (2012), "the correlation between connectivity and global integration is an important indicator of how clear an urban system is for its users; and is called as 'intelligibility"' (as cited in Kaushik [2016: 28]). It is a matter of discussion that it is the degree to which large scale system can be comprehended with reference to understanding of local system of spatial configuration without conscious efforts (Hillier, 2007). Thus, intelligibility is a key property of the spatial structure of towns and cities. It indicates the quality of an environment and further defines its easy navigability and understanding. Therefore, the relation between connectivity of space and its global integration leads to the understanding of the spatial configuration from the point of view of its constituent parts.

It means that, the most integrated area will be visited more: making it a relatively familiar area, even though integration has no direct effect on familiarity. In an intelligible system of spaces the well-integrated spaces are also well connected also and vice-versa.

The intelligible world has a perfect correlation between local and global properties of space, so the whole system is legible from this point/perspective. On the other hand, unintelligible environment has poor correlation, so the people tend to lose their way more often there.

With the help of a scattergram, this notion can be best explained. It shows the correlation between connectivity and integration (Hillier, 2007). According to Hillier, if the dots or points in the scattergram form a straight line rising at 45 degree from bottom left to top right and the dots fit close to the line, then this implies a good correlation between local and global integration. Consequently, the system would be highly intelligible (Hillier, 2007).

\section{Synergy}

"The relationship between local integration (R3) and global integration (Rn), is called synergy. It indicates the relationship between parts of the spatial system to whole system" (Choudhary and Adane [2012] as cited in Kaushik [2016: 28]). Synergy can simply be defined as the correlation between local (Radius 3) and global integrations. It is a different kind of intelligibility. It is more about the relationship between the local and global structure. Radius 3 is the best correlate, for example, of pedestrian movement rates and seems to give a good indication of the local pedestrian scale structure of urban areas.

It is a correlation between the local and global parameters, reflecting how the global structure of an entire entity like a city or city region is expressed in the local structure of space. The correlation value ( $r$ square) shall be between 0.0 and 1.0, where 1.0 reflects a perfect correlation (either positive or negative) between the local and global system, and a value of 0.0 indicates no or a random correlation (Mahmoud, 2010).

\section{STUDY AREA}

Gurgaon city has been master planned and developed over a period of time and has different planning and development strategies which are manifested in its urban development. The planned growth of the city took place after the inception 
of HUDA in 1977 (Mehtani, 2012). It has been nearly 40 years of development and yet it has not been uniform. Gurgaon is a city that represents dynamism of growth. This city forms a part of National Capital Region (NCR). From the urban design point of view, the city can be understood by understanding its morphology. It developed over a period of time and in order to understand the morphology of the city it is best to understand and compare the morphology of its different sectors with distinct urban form developed during different time periods.

\section{Why Sectors 4, 56 and $49 ?$}

The neighbourhood Sectors no. 4, 56 and 49 have been identified for the matter of comparison between different typologies. Sector 4 is a completely low rise plotted development while Sector 56 is a mix of low rise and high rise cooperative group housings and Sector 49 has a mix of private low rise and high rise group housing projects. All the three sectors are representatives of three prominent typological developments in the city as mentioned above; hence these are selected as study areas. The locations of the three sectors are as shown in Figure 1. Sector 4 lies in the northern part of the city whereas Sectors 56 and 49 lie close by in the southern or new part of Gurgaon.

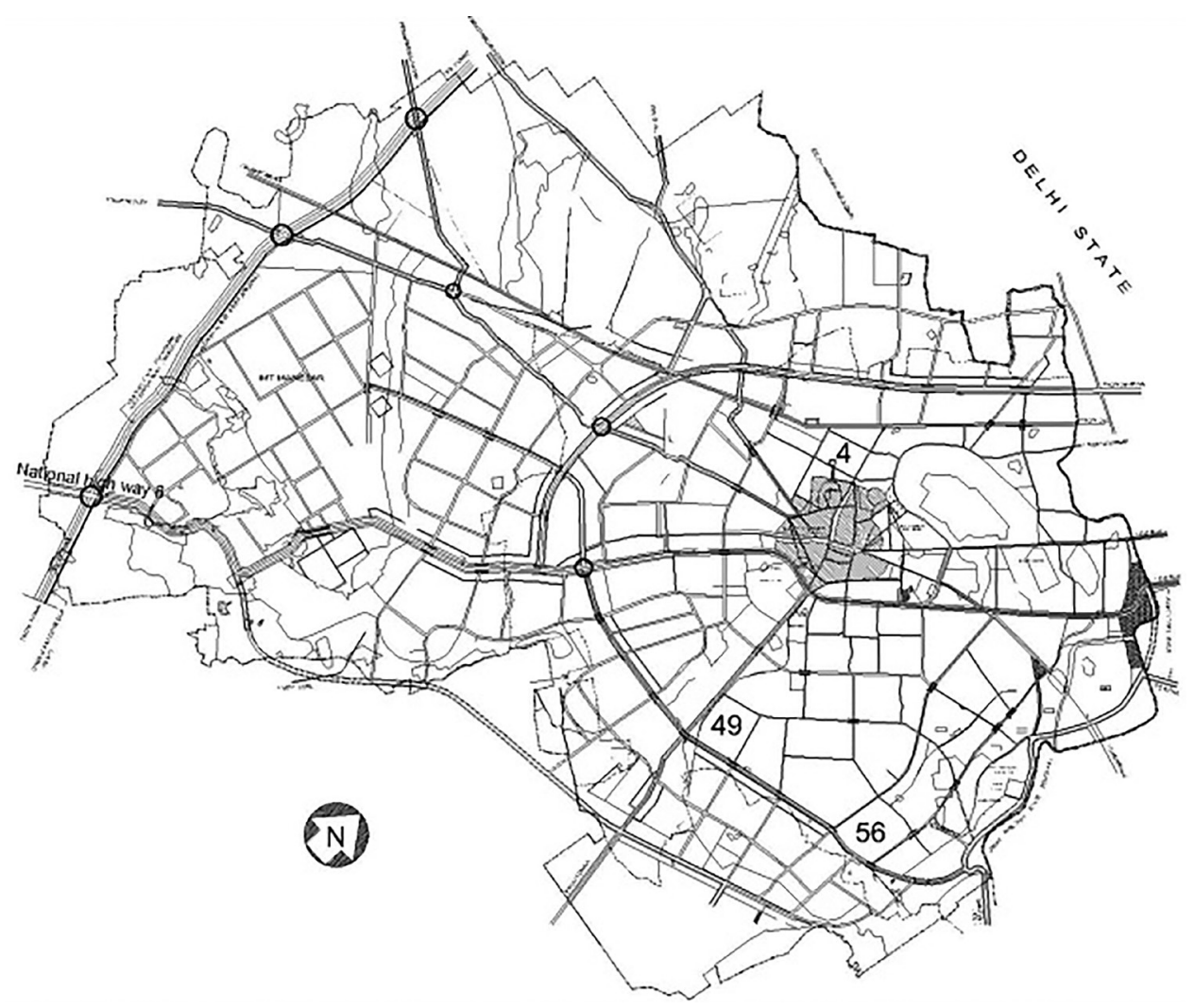

Figure 1. Location of the Three Sectors in City of Gurgaon (Sectors 4, 56 and 49) 


\section{Sector 4}

Sector 4 is amongst the earliest developed sectors of the city. It was developed during 1975-1978 (Mehtani, 2012). The residential morphology of the sector comprises of low rise plotted development. The plot sizes range from 125 sq yards to $500 \mathrm{sq}$ yards. There are four schools and a commercial centre located on an $18 \mathrm{~m}$ wide road in the sector. The commercial area lies in the centre of the sector, which makes it easily accessible from all sides, besides having other amenities. A typical orthogonal street network pattern was adopted for the development of this sector which shown in Figure 2.

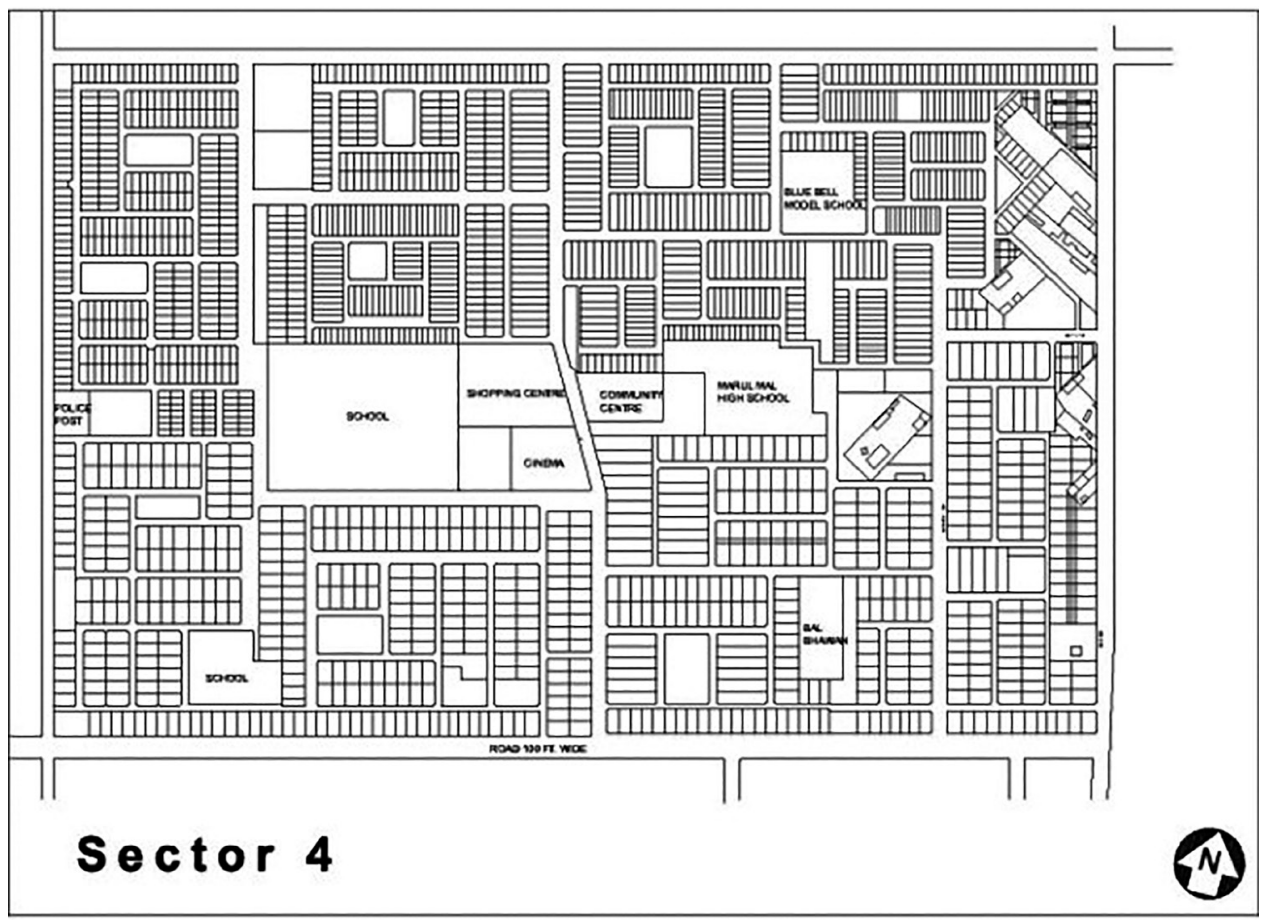

Figure 2. Plan of Sector 4

\section{Sector 56}

Mehtani says that this sector was developed during the year 2000 (Mehtani, 2012). The morphology of this residential sector comprises of plotted development by HUDA along with 83 group housings. The plot sizes of group housing vary from half an acre to over 15 acres. The plotting for group housing has been done by HUDA itself. One drain divides the sector diagonally in two parts. A $30 \mathrm{~m}$ wide major road, running in the east-west direction, passes through the centre of the sector. The spread of group housing plots is a major morphological feature in the northern part of the sector. There are eight schools and a commercial centre surrounded by roads on 
three of its sides in the sector. The commercial area lies in the middle of the sector, which is easily accessible from all sides, besides the presence of other amenities. The plotted sector development is a typical prototype of orthogonal street network system which shown in Figure 3.

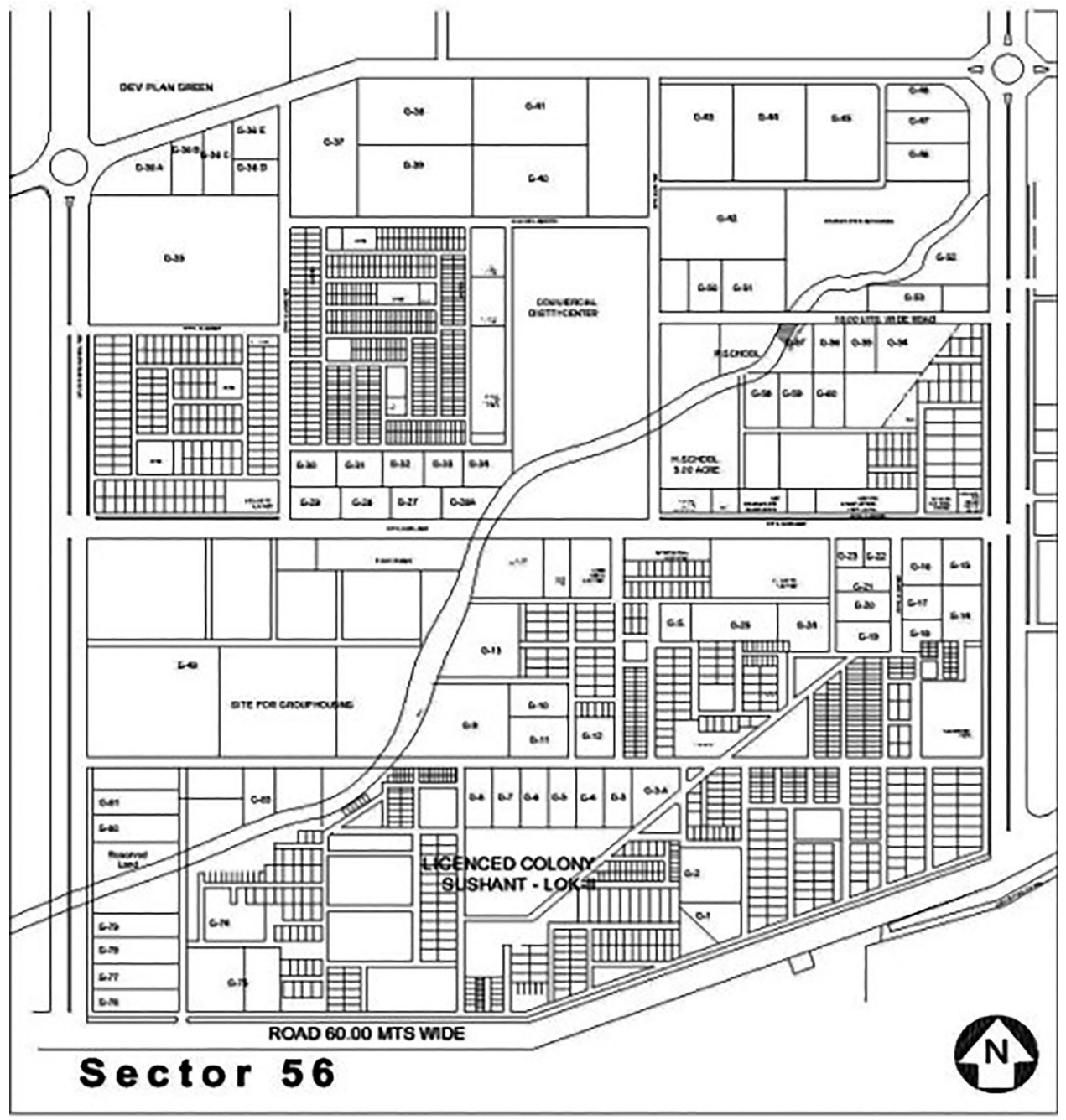

Figure 3. Plan of Sector 56 


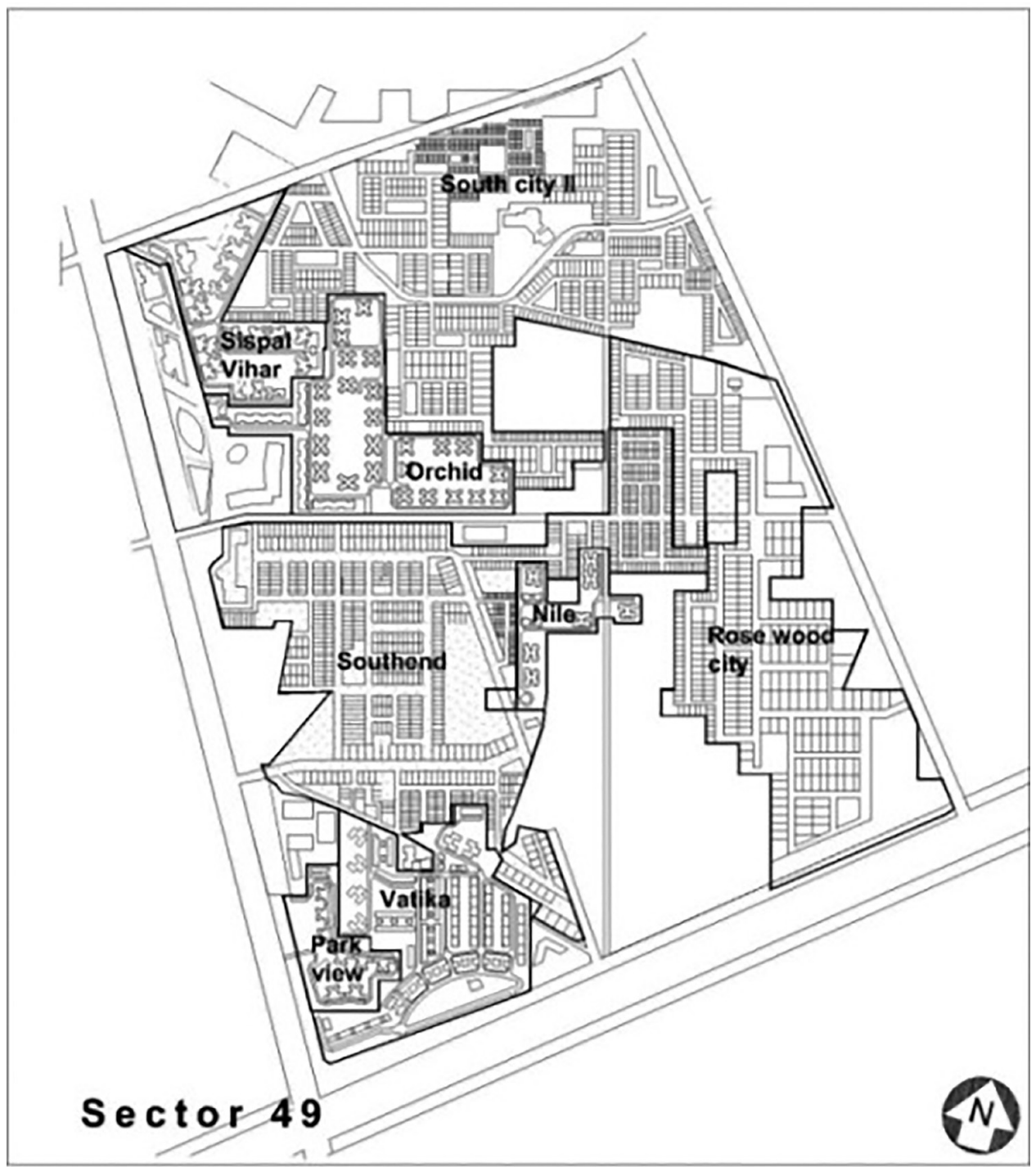

Figure 4. Plan of Sector 49

\section{Sector 49}

This sector has a mixed development and was developed during the year 1995-2000 (Mehtani, 2012). This sector is developed with the initiative of private developers. All the developments in the sector are gated and guarded. There are five high rise group housing namely Nile, Vatika, Parkview, Sispal Vihar and Orchid Petals. There is a series of low rise row housing and plotted development on individual plots. The plan of the sector can be referred in Figure 4. 


\section{METHODOLOGY}

\section{Why Space Syntax?}

Space syntax is a theory suggested by Hillier and his colleagues at Bartlett School of Architecture in the United Kingdom (Lee et al., 2014: 38). It is prominently described by using relative depth of axes or spaces in order to calculate the hierarchical configuration of spaces. Such technique is broadly used in studies of cities to understand the formation of constituent neighbourhoods. It is definitely a meaningful tool to objectively identify and categorise spatial hierarchy. Space syntax theory had not been applied earlier in the context of Gurgaon city earlier. Hence, it is a significant tool used to understand the distinguished morphology of the sectors of Gurgaon.

The study of street pattern is inclusive of overall configuration and syntactical parameters like depth, connectivity, global and local integration, intelligibility and synergy. These parameters have already been defined so that one can understand the implications of by various syntactical parameters.

\section{Method of Preparing Syntactic Axial Map}

After understanding the syntactical parameters, axial maps of the three selected neighbourhoods namely Sector 4, 56 and 49 of Gurgaon city were drawn. First, the Auto-CAD drawing of the three sectors was drawn. Then it was saved in *.dxf file format. This is because the Depthmap software support files in the form of * ${ }^{\text {. dxf format }}$ and not *.dwg format. After the *.dxf file was saved, the same file was imported to the Depthmap software for axial graph analysis. The axial map was prepared in Depthmap software (created by Alasdair Turner, www.bartlett.ucl.ac.uk). It is an application used for visibility analysis of architectural system. "Axial map of an area consists of the fewest and the longest sets of lines till all entire spaces are covered. Once an axial map is obtained, it can be used to get various values of properties of the geometry of the area" (Mohammed, 2010).

\section{Data Collection}

The data required for analysis of the axial map generated on Depthmap software were Auto-CAD drawings in *.dxf format. The Auto-CAD drawings were obtained from the office of the Town and Country Planning Organization, Gurgaon. However, because Sector 49 is developed by private initiative, therefore the data were compiled by collecting the maps from individual developers separately. The individual maps thus collected, were put together in the form of a one complete sector map in Auto-CAD drawing. 


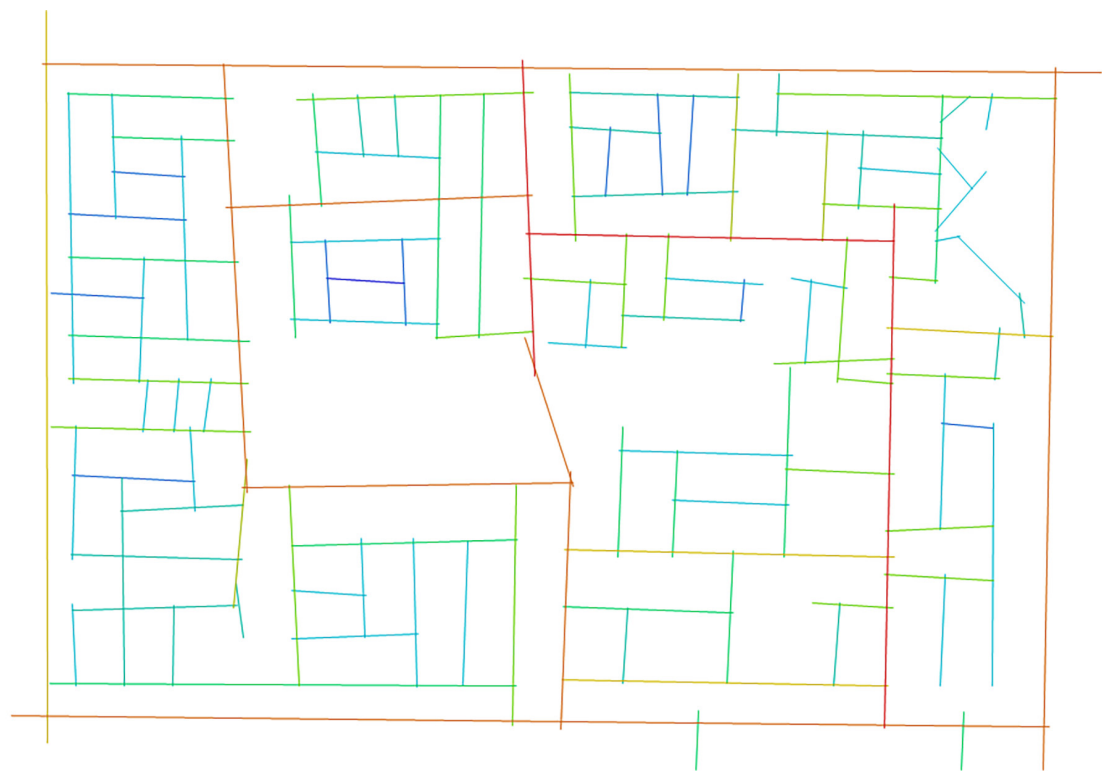

Figure 5(a). Global Integration (Rn): Sector 4

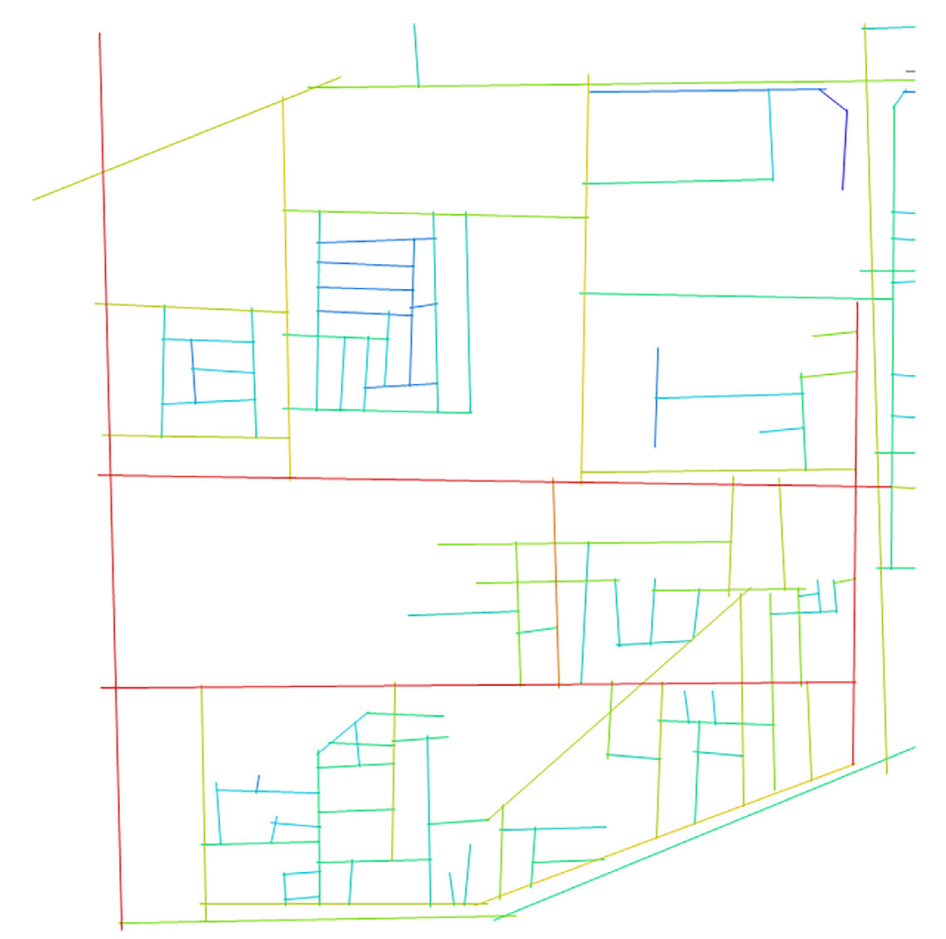

Figure 5(b). Global Integration (Rn): Sector 56 


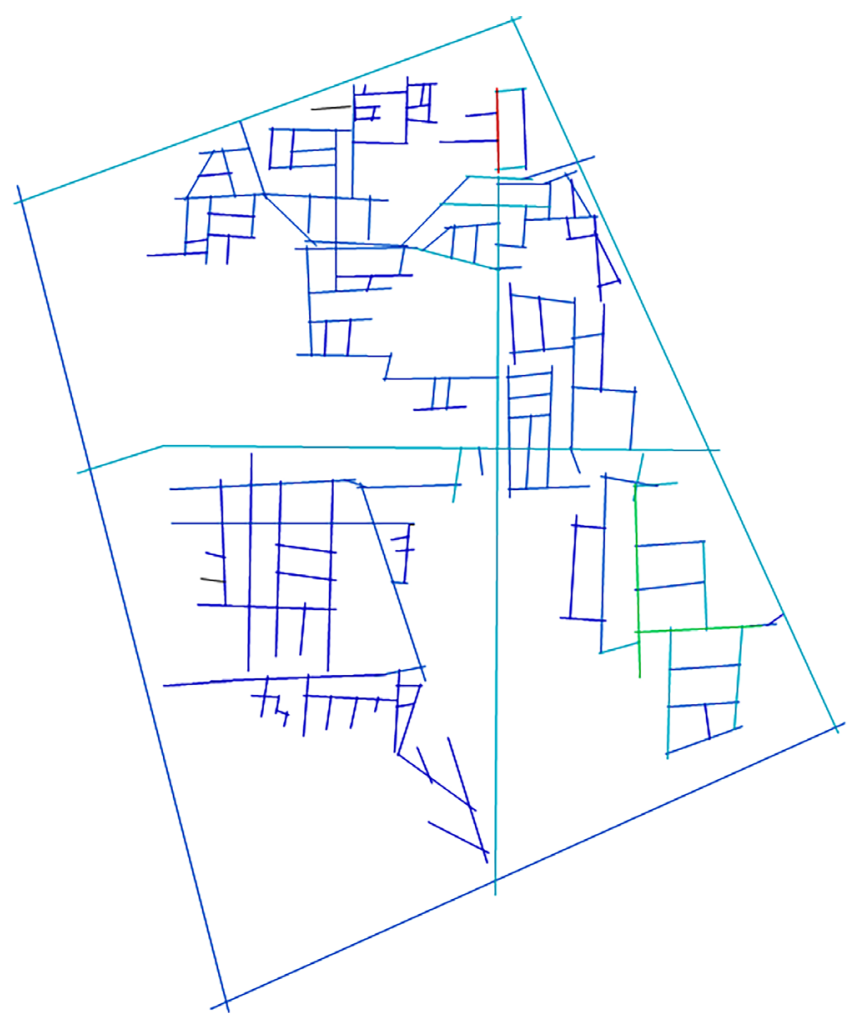

Figure 5(c). Global Integration (Rn): Sector 49

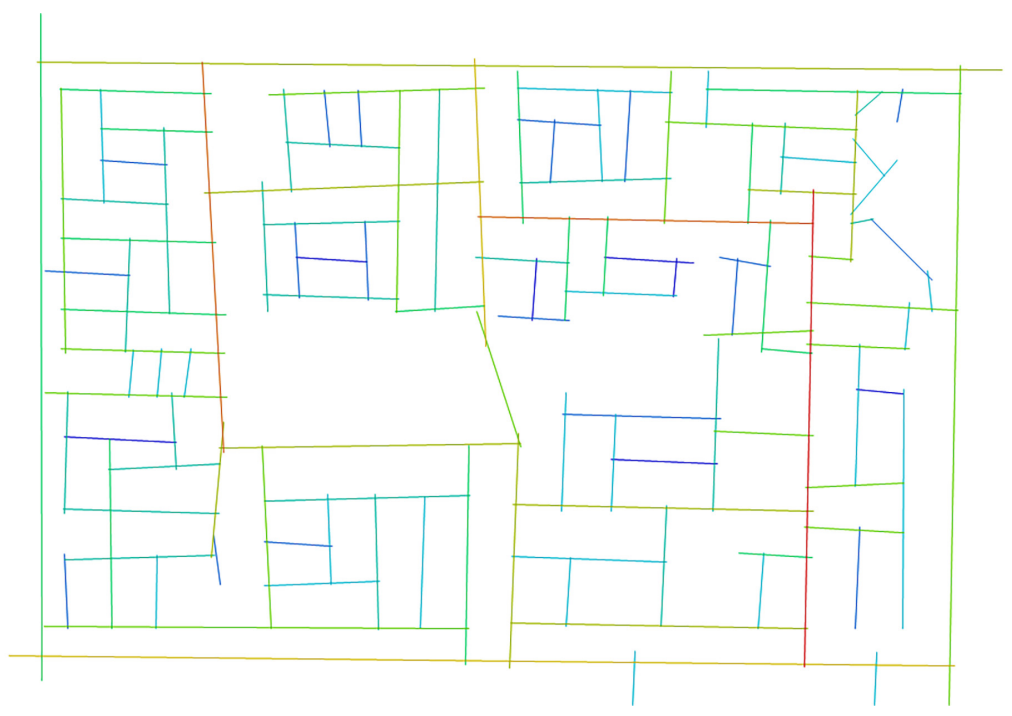

Figure 6(a). Local Integration (R3): Sector 4 


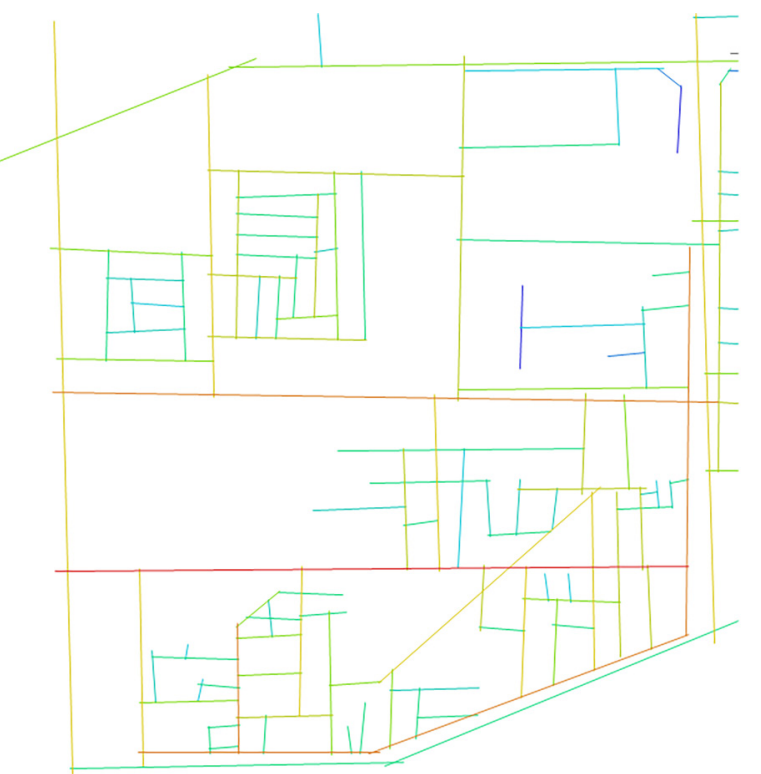

Figure 6(b). Local Integration (R3): Sector 56

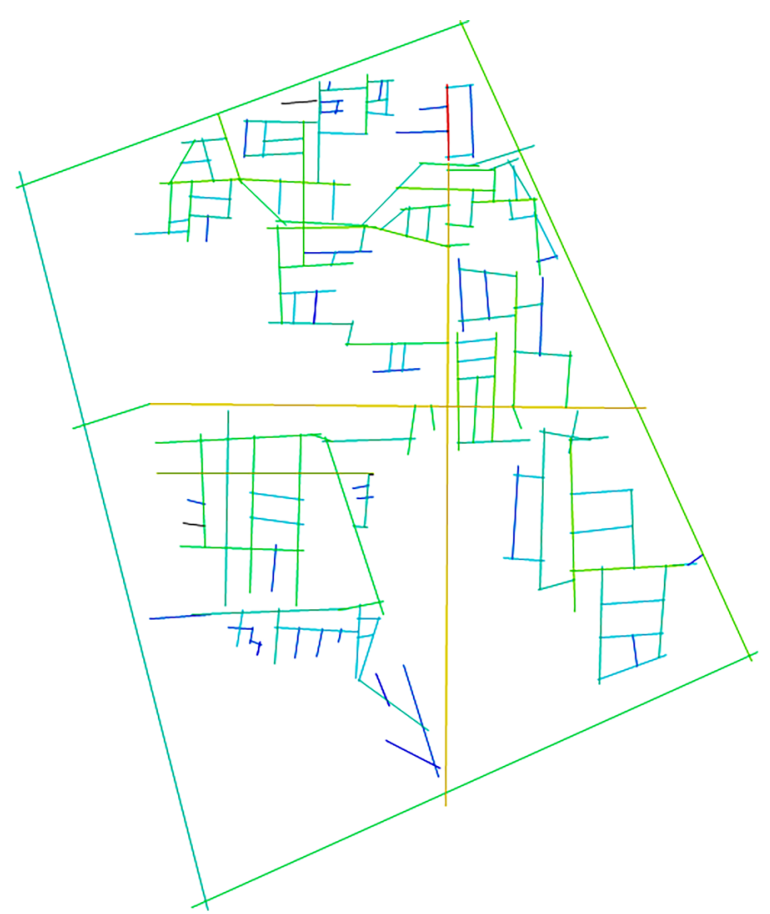

Figure 6(c). Local Integration (R3): Sector 49 


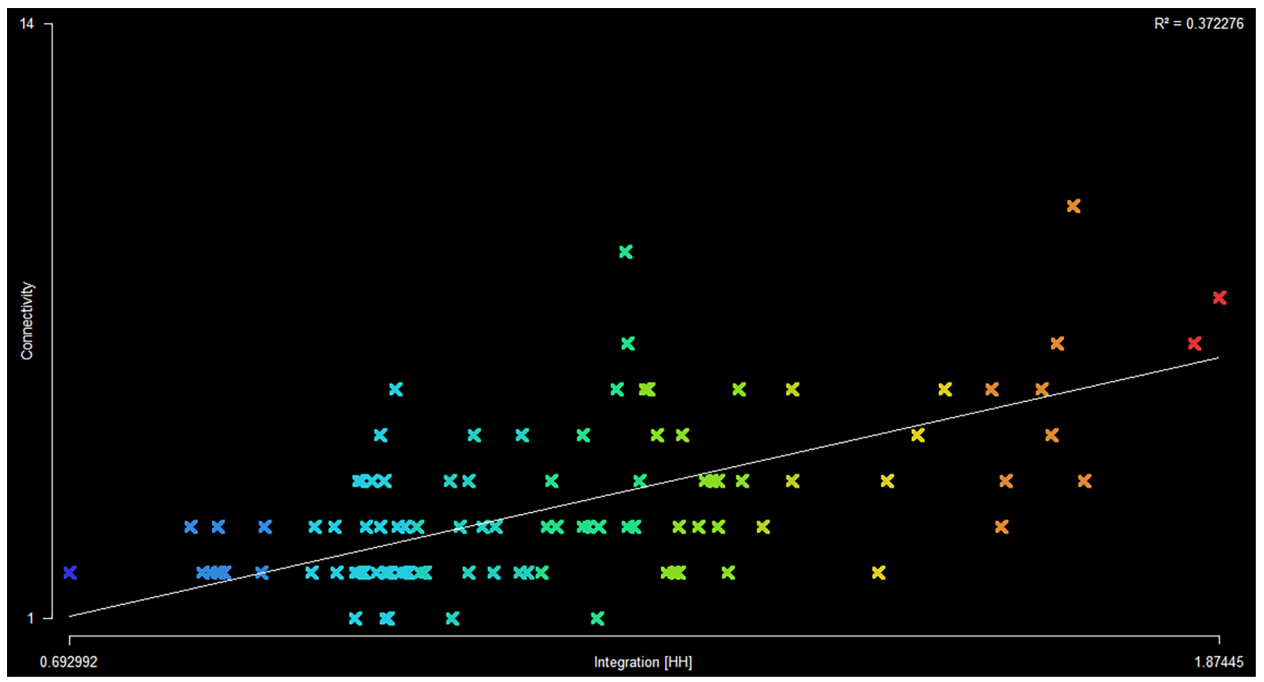

Figure 7(a). Intelligibility, Sector 4, R2: 0.372276

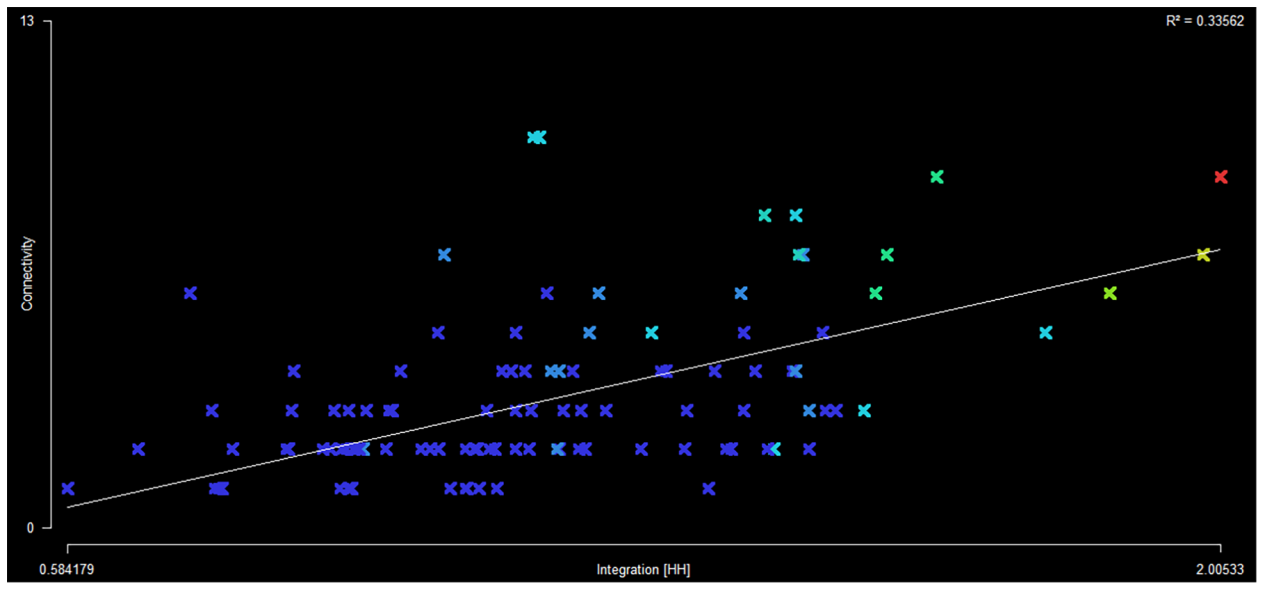

Figure $7(b)$. Intelligibility, Sector 56, R2: 0.33562 


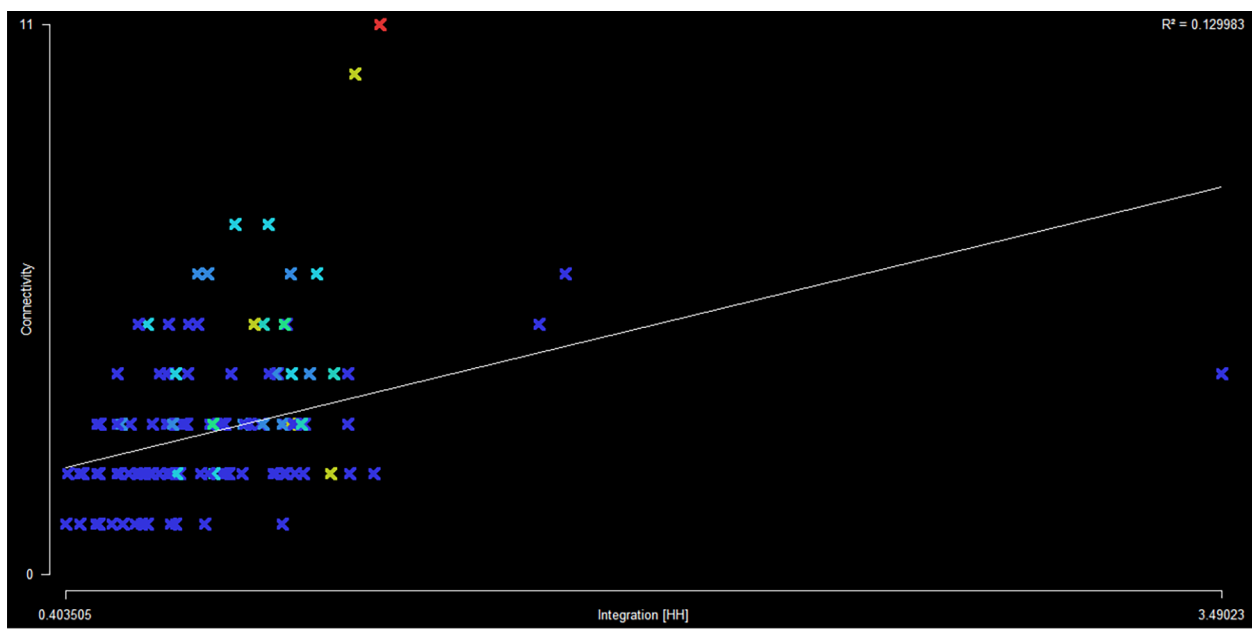

Figure 7(c). Intelligibility, Sector 49, R2: 0.129983

Based on the intelligibility scattergrams, which is the correlation between the global integration (Rn) and connectivity, Sector 49 is the least intelligible.

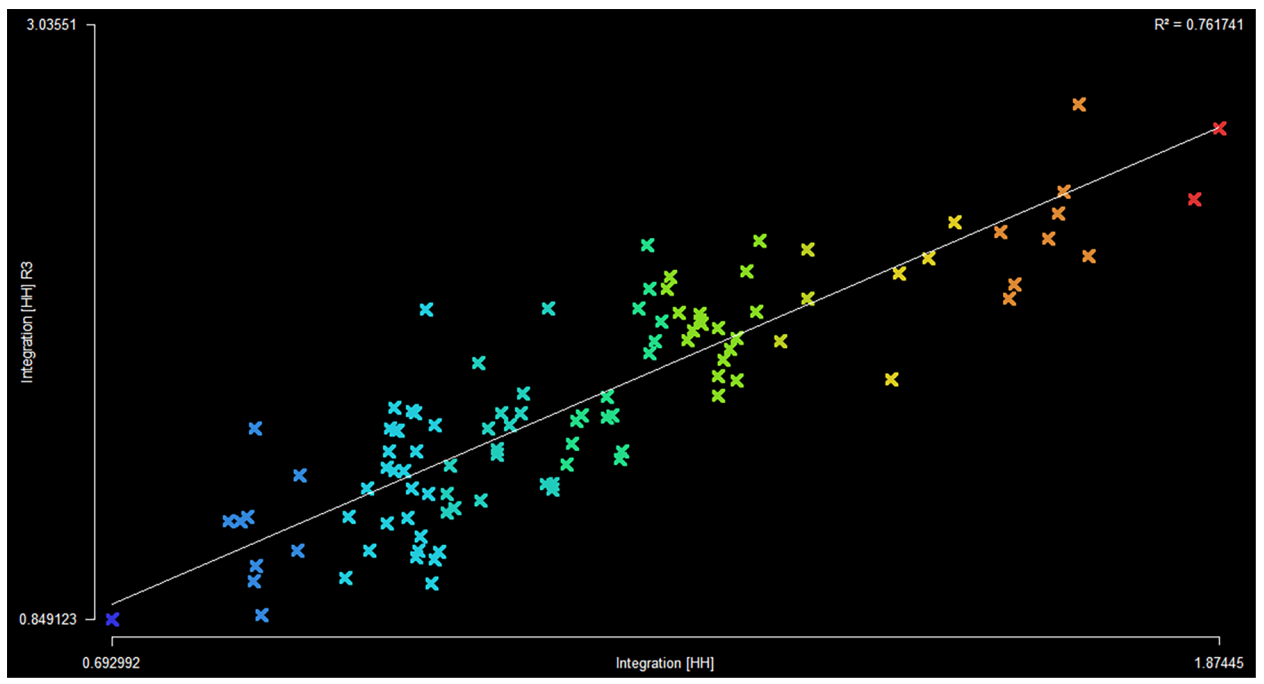

Figure 8(a). Synergy, Sector 4, R2: 0.761741 


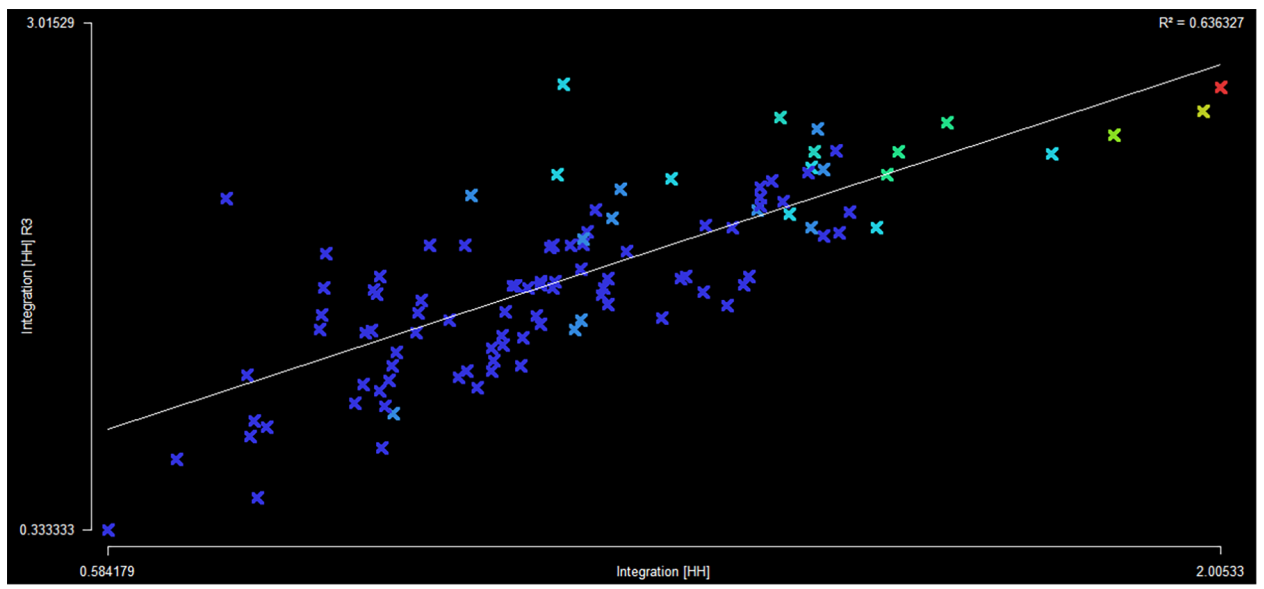

Figure 8(b). Synergy, Sector 56, R2: 0.636327

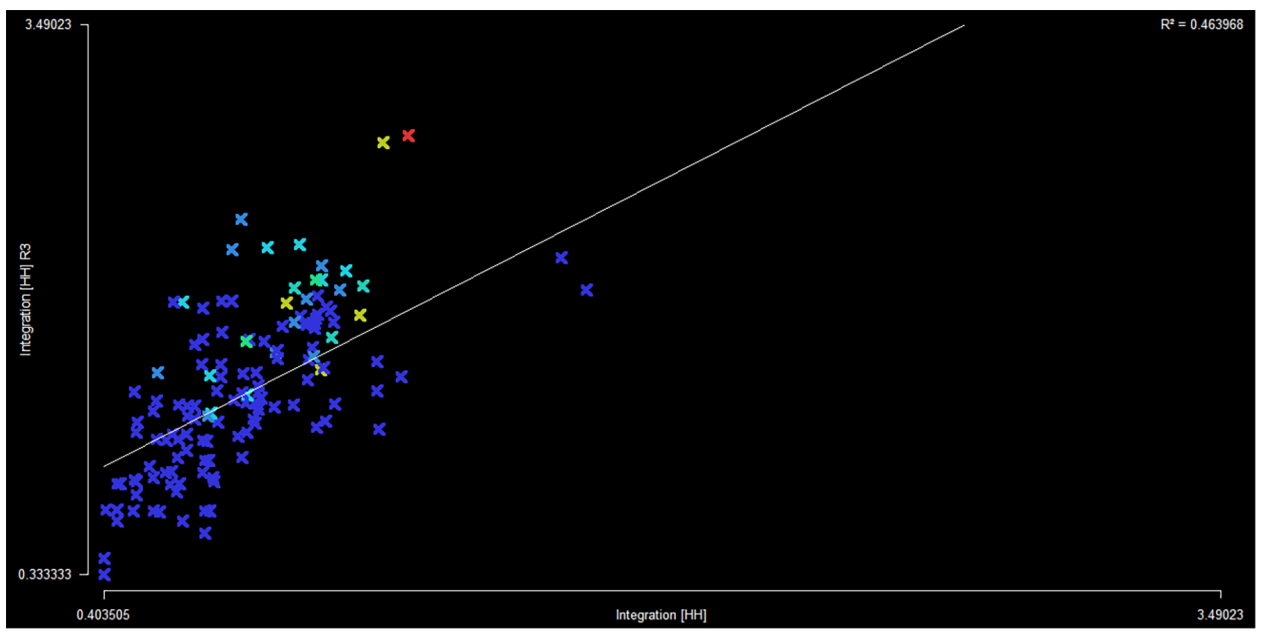

Figure 8(c). Synergy, Sector 49, R2: 0.463968

The synergy is a correlation between global integration (Rn) and local integration (R3) and according to the data produced by the synergy scattergrams, Sector 49 has the least synergy. 

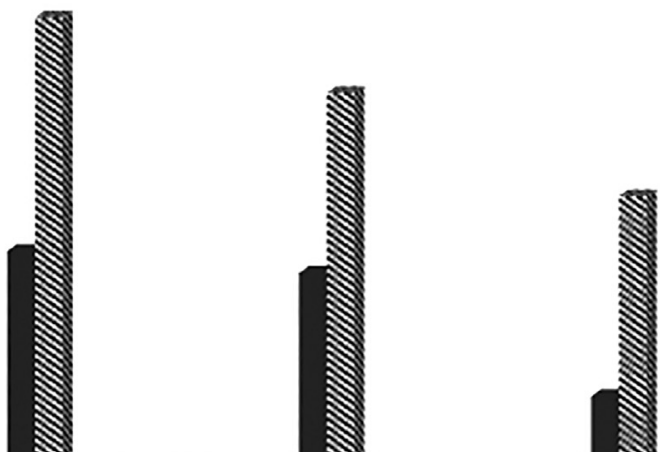

- Intellig

\% Synerc

Figure 9. Comparison of Intelligibility and Synergy of the Three Sectors

Apart from that, the values of different parameters are obtained and are enumerated in Table 1 as follows.

Table 1. Various Syntactical Parameters

\begin{tabular}{lccc}
\hline \multicolumn{4}{c}{ Space Syntax Parameters } \\
\hline \multicolumn{1}{c}{ Parameters } & Sector $\mathbf{4}$ & Sector 56 & Sector 49 \\
\hline Line length avg. & 233.457 & 272.284 & 203.021 \\
Line length min. & 35 & 16.5723 & 13.3348 \\
Line length max. & 1487.12 & 1668.36 & 1990.89 \\
Connectivity avg. & 3.41463 & 3.22222 & 2.8 \\
Connectivity min. & 1 & 1 & 1 \\
Connectivity max. & 14 & 13 & 11 \\
Global integration (Int HH) avg. & 1.18895 & 1.17071 & 0.798856 \\
Int HH min. & 0.69299 & 0.58418 & 0.403505 \\
Int HH max. & 1.87445 & 2.00533 & 3.49023 \\
Int R3 avg. & 1.63771 & 1.65882 & 1.37191 \\
Int R3 min. & 0.84912 & 0.33333 & 0.33333 \\
Int R3 max. & 3.03551 & 3.01529 & 3.49023 \\
Intelligibility & 0.37228 & 0.33562 & 0.129983 \\
Synergy & 0.76174 & 0.63633 & 0.463968 \\
\hline
\end{tabular}

\section{RESULTS AND CONCLUSION}

With the help of axial plans of sectors, it can be observed that axial map of Sector 4 consists of 123 axial lines, Sector 56 has 125 lines and the axial map of Sector 49 has 169 lines (Figures 5 and 6). The global integration and local integration for each of the three sectors are mapped in Figures 5(a), (b), (c) and 6(a), (b), (c) respectively. 
The red and orange lines shown in the maps are most integrated whereas the blue and the purple lines are least integrated. The higher order measure of space syntax, i.e degree of intelligibility can be easily read and understood with the help of scattergram. The scattergram depicting intelligibility shows relation between Int $\mathrm{Rn}$ and connectivity. It is a graph with Int $\mathrm{Rn}$ values on $\mathrm{x}$-axis and connectivity values on $y$-axis. Each dot in the scattergram represents one axial line with $x$ - and $y$-values. Any system's or configuration's intelligibility is a correlation between global and local variables. The $R 2$ values describe the extent the scatter of a point fit to a line. If they fit exactly on to a line, then the $R 2$ is 1 . Both integration and connectivity perfectly predict each other (Mohammed, 2010). This is rather a tough condition to be achieved in reality.

If $R 2$ is 0 then one can argue that the pattern of dots is random and Int $R$ n and connectivity are unrelated. This kind of spatial system is completely unintelligible.

It can be observed from Figure 7 (a) that the dots in scattergram of Sector 4 are comparatively closely fit to a line and the $R 2$ value is 0.372276 . Intelligibility values can be used to comprehend different environment. The layout of Sector 4 has high intelligibility values. It means that at local level, any person can easily comprehend and grasp the overall configuration of the system. It can be argued that Sector 4 presents a layout that offers its users better understanding of local system configuration. With the local variable and stronger correlations more global configuration of space can be inferred.

The $R 2$ value of Sector 56's scattergram (Figure 7[b]) is close to Sector 4 with value of 0.33562 , whereas the $R 2$ value of Sector 49 (Figure 7 [c]) which is completely gated is merely 0.129983. It means that the layout of Sector 49 is less intelligible as compared to Sector 4 and 56. The intelligible world has the perfect correlation between local and global properties of space, so the whole system is legible from that part. On the other hand, unintelligible environment has poor correlation, so the people tend to lose their way. In a weaker correlation, people fail to learn about large patterns from their experience of smaller parts.

Synergy is the relation between the global and local properties of integration. The Int $\mathrm{Rn}$ are represented on $\mathrm{x}$-axis whereas the Int $\mathrm{R} 3$ values are represented on $y$-axis. Thus, each dot represents an axial line with $x$ - and $y$-values. The Figure 8(a), (b) and (c) show the synergy scattergrams. It is obvious from the figure that the dots representing the axial lines in the scattergram of Sector 4 are tightly placed and fit into a line with the $R 2$ value is 0.761741 while Sector 56 has a little less $R 2$ value (R2: 0.636327 ) whereas the $R 2$ value of Sector 49 is just 0.463968 . The scattergram of Sector 49 is a little diffused and points do not form any firm line indicating poor correlation. This value means that Sector 49 has least synergy and one cannot predict the global pattern from the understanding of local pattern.

The results from the three case studies, when compared sectors showed a clear difference between the spatial configuration of the three sectors. Sector 4 has shown the highest intelligibility and Sector 49 has the lowest degree of intelligibility (almost one third the value of Sector 4).

The degree of synergy of Sector 49 is the lowest compared to the other two sectors. It also indicates that order of synergy and intelligibility is the highest in case of Sector 4 and lowest is case of Sector 49. 


\section{Contribution of the Study on Existing Body of Space Syntax Literature}

The space syntax literature had not dealt with the aspects of Gated community. This paper has made an attempt to bring out specific spatial differences between the street patterns of three different neighbourhoods that are gated and non-gated. Use of space syntax method in the analysis opens up avenue for further research in spatial configurations in gated community/development.

\section{Major Implications of the Study}

The study at one point brings out spatial configurational differences between the three different neighbourhoods. The issues of characteristic differences that have negative impact on the street usage and morphology need to be addressed. Since, the construction of gated neighbourhood is very much in fashion nowadays, one keep in account the overall integrity of the street system. The street morphology may not look like a piece of design work by different architects and planners. Rather one should be able to navigate through the gated areas so as to have better understanding of overall configuration and better perception and cognition. The research brings out importance of non-gated areas and lays stress on other means of making neighbourhoods safe. Gating is a phenomenon, to make neighbourhood safe, but that should equally address the issues of negative impact of gating on overall accessibility, walkability, etc. Thus the study opens up an avenue for thought, to make less and less of gated development in order to make neighbourhood streets easily accessible and navigable. There is a need to focus upon making streets easily identifiable/recognisable and better understood.

\section{ACKNOWLEDGEMENT}

This paper is a work of ongoing PhD research of the author under the supervision of Professor Dr Jyoti Pandey Sharma, Deenbandhu Chhotu Ram University of Science and Technology (DCRUST), Murthal, Haryana, India. Without her timely advice, this research would not have been possible.

\section{REFERENCES}

Choudhary, P. and Adane, V. (2012). Spatial configurations of the urban cores in central India. Proceedings: Eighth International Space Syntax Symposium. Santiago, Chile: Pontifical Catholic University of Chile, 1-19.

Department of Town and Country Planning, Haryana (2010). Sub-Regional Plan for Haryana Sub-Region of NCR-2021. Chandigarh, India: The Department of Town and Country Planning, Government of Haryana.

Dettlaff, W. (2014). Space syntax analysis: Methodology of understanding the space. PhD Interdisciplinary Journal, 283-291.

Government of India (2011). District Census Handbook Gurgaon. New Delhi: Office of the Registrar General and Census Commissioner.

(1991). 1991 Census Hand Book. New Delhi: Office of the Registrar General and Census Commissioner. 
Hillier, B. (2007). Space is the Machine. London: Space Syntax.

Hillier, B. and Hanson, J. (1984). The Social Logic of Space. Cambridge: Cambridge University Press.

Kaushik, A. (2016). Space syntax: A tool for smart and analytical investigation into urban settings. Journal of the Indian Institute of Architects, 81 (11): 23-28.

Lee, J.S., Hong, W.H. and Jeong, G.O. (2014). Analysis of space syntax characteristics in roads around temporary relief area: Case study of Sewol disaster. Paper presented at the International Conference on Biological, Environment and Food Engineering (BEFE-2014). Bali, Indonesia, 4-5 August.

Long, Y. (2007). The relationship between objective and subjective evaluations of the urban environment: Space syntax, cognitive maps and urban legibility. PhD diss. North Carolina State University.

Mahmoud, A.H. (2010). Integrating space syntax theory in sustainable planting design of parks. Proceeding: First International Conference on Sustainability and the Future (FISC 2010). Elshourouq, Egypt: The British University in Egypt.

Mehtani, P.C. (2012). Growth, development and sustainability of cities: A case study of Gurgaon. PhD diss. University of Delhi.

Mohammed, A.A. (2010). Spatial conditions for sustainable communities: The case of informal settlements in GCR. MSc diss. Ain Shams University, Cairo

Paul, A. (2011). Axial analysis: A syntactic approach to movement network modelling. Institute of Town Planners, India Journal, 8(1): 29-40.

Rajagopalan, S. and Tabarrok, A. (2014). Chapter 10: Lessons from Gurgaon, India's private city. In David E.A. and Stefano M. (eds.), Cities and Private Planning. Cheltenham, UK: Edward Elgar Publishing.

United Nations Population Fund (UNFPA) (2007). State of World Population 2007: Unleashing the Potential of Urban Growth. New York: UNFPA. Available at: www.unfpa.org/sites/default/files/pub-pdf/695_filename_sowp2007_eng.pdf [Accessed on 5 November 2016). 